\title{
Stable gastric pentadecapeptide BPC 157 can improve the healing course of spinal cord injury and lead to functional recovery in rats
}

Darko Perovic ${ }^{1}$, Danijela Kolenc ${ }^{2}$, Vide Bilic ${ }^{1}$, Nenad Somun ${ }^{1}$, Domagoj Drmic ${ }^{1}$, Esmat Elabjer $^{1}$, Gojko Buljat $^{1}$, Sven Seiwerth ${ }^{2}$ and Predrag Sikiric ${ }^{1^{*}}$ (D)

\begin{abstract}
Background: We focused on the therapeutic effects of the stable gastric pentadecapeptide BPC 157 in spinal cord injury using a rat model. BPC 157, of which the LD1 has not been achieved, has been implemented as an anti-ulcer peptide in inflammatory bowel disease trials and recently in a multiple sclerosis trial. In animals, BPC 157 has an anti-inflammatory effect and therapeutic effects in functional recovery and the rescue of somatosensory neurons in the sciatic nerve after transection, upon brain injury after concussive trauma, and in severe encephalopathies. Additionally, BPC 157 affects various molecular pathways.

Methods: Therefore, BPC 157 therapy was administered by a one-time intraperitoneal injection (BPC 157 (200 or $2 \mu \mathrm{g} / \mathrm{kg}$ ) or $0.9 \% \mathrm{NaCl}(5 \mathrm{ml} / \mathrm{kg})) 10 \mathrm{~min}$ after injury. The injury procedure involved laminectomy (level L2-L3) and a 60-s compression (neurosurgical piston (60-66 g) of the exposed dural sac of the sacrocaudal spinal cord). Assessments were performed at 1, 4, 7, 15, 30, 90, 180, and 360 days after injury.

Results: All of the injured rats that received BPC 157 exhibited consistent clinical improvement, increasingly better motor function of the tail, no autotomy, and resolved spasticity by day 15. BPC 157 application largely counteracted changes at the microscopic level, including the formation of vacuoles and the loss of axons in the white matter, the formation of edema and the loss of motoneurons in the gray matter, and a decreased number of large myelinated axons in the rat caudal nerve from day 7. EMG recordings showed a markedly lower motor unit potential in the tail muscle.
\end{abstract}

Conclusion: Axonal and neuronal necrosis, demyelination, and cyst formation were counteracted. The functional rescue provided by BPC 157 after spinal cord injury implies that BPC 157 therapy can impact all stages of the secondary injury phase.

Keywords: BPC 157, Injury, Rats, Spinal cord

\footnotetext{
* Correspondence: sikiric@mef.hr

${ }^{1}$ Department of Pharmacology, School of Medicine, University of Zagreb,

Salata 11, P.O. Box 916, 10000 Zagreb, Croatia

Full list of author information is available at the end of the article
}

(c) The Author(s). 2019 Open Access This article is distributed under the terms of the Creative Commons Attribution 4.0 International License (http://creativecommons.org/licenses/by/4.0/), which permits unrestricted use, distribution, and reproduction in any medium, provided you give appropriate credit to the original author(s) and the source, provide a link to the Creative Commons license, and indicate if changes were made. The Creative Commons Public Domain Dedication waiver (http://creativecommons.org/publicdomain/zero/1.0/) applies to the data made available in this article, unless otherwise stated. 


\section{Introduction}

We focused on the application of the stable gastric pentadecapeptide BPC 157 [1-11] to improve the outcomes of spinal cord injury in rats.

Spinal cord injury generally involves the preclusion of neural relays across the lesion site and is thereby predictably associated with a lack of functional improvement $[12,13]$. On the other hand, there is evidence that spinal cord injury triggers a cascade of secondary degenerative events that cause further damage to the injured area and induce local inflammation along with hemorrhage and edema $[12,13]$ and that the therapeutic agents imatinib (which has been shown to inhibit cytokine production and reduce hemorrhage, edema, and inflammation) [14] and ibuprofen initiate favorable axonal growth and functional recovery through Rho inhibition [15]. Likewise, there is favorable evidence to support the engraftment of neural stem cells [16] or bone marrow stromal cells [17] into the lesion site. However, there are disputes about the relevant applicability of this evidence $[18,19]$, particularly considering the low survival rate of bone marrow stromal cells transplanted into the contused adult rat spinal cord $[20,21]$ and the need to completely fill the lesion site with neural stem cells [22]. Consequently, there have been attempts to improve the therapeutic effectiveness with combined treatments (i.e., neural stem cells with fibrin and a growth factor cocktail (BDNF; NT-3; mGDNF; IGF; bFGF; EGF; PDF; aFGF; and HGF) [23] or bone marrow stromal cells with the application of cyclosporine, minocycline, and methylprednisolone [24]). Likewise, considering the beneficial effect of the deletion of the Nogo Receptor 1 (NgR1) gene, a sequential combination of Nogo-A suppression (by anti-Nogo-A antibody treatment) and treadmill rehabilitative training was examined [25].

It is generally believed that further attempts are fully justified [26]. In comparison, the stable gastric pentadecapeptide BPC 157, an emerging treatment with potential therapeutic applications, appears to be unrestricted by the limitations seen in previous therapies. The stable gastric pentadecapeptide BPC 157, an original cytoprotective antiulcer peptide that is used in ulcerative colitis and recently in a multiple sclerosis trial and that has an LD1 that has not been achieved [1-11], is known to have pleiotropic beneficial effects [1-11] and to interact with several molecular pathways [2, 27-32]. BPC 157 has beneficial effects on inflammation, hemorrhage, and edema after traumatic brain injury [33], various severe encephalopathies (which follow gastrointestinal and/or liver lesions), NSAID overdose [34-37], or insulin overdose seizures [38] and on severe muscle weakness after exposure to the specific neurotoxin cuprizone in a rat multiple sclerosis model [39] or magnesium overdose [40]. In other studies, it was shown that BPC 157 counteracts increased levels of proinflammatory and procachectic cytokines such as IL-6 and TNF- $\alpha$ [2]. Finally, BPC 157 improves sciatic nerve healing [41] when applied intraperitoneally, intragastrically, or locally at the site of anastomosis shortly after injury or directly into the tube after non-anastomosed nerve tubing (7mm nerve segment resection).

Therefore, we used a model of spinal cord injury that has many characteristics found in human spastic syndrome [42] and can be used long-term to provide a realistic model of spasticity development in the tail muscle.

The administered therapy was a one-time intraperitoneal application of the stable gastric pentadecapeptide BPC 157, much like the one-time engraftment of neural stem cells [16] or bone marrow stromal cells [17] into the lesion site. This experiment will provide evidence that BPC 157 treatment can recover tail function, resolve spasticity, and improve neurologic recovery.

\section{Materials and methods Animals}

Wistar albino male rats (aged 12 weeks, 350-400 g b.w.) were bred in-house (the animal facility at the Department of Pharmacology, School of Medicine, Zagreb, Croatia; registered by Directorate of Veterinary; Reg. No: HR-POK-007), acclimated for 5 days, and randomly assigned to experimental groups (at least 6 animals per experimental group and interval). The experiments were approved by the Local Ethics Committee. The laboratory animals were housed in $\mathrm{PC}$ cages in conventional laboratory conditions at a temperature of $22.4{ }^{\circ} \mathrm{C}$, a relative humidity of $40-70 \%$, and a noise level of $60 \mathrm{~dB}$. Each cage was identified by the date, study number, group, dose, number, and sex of each animal. Fluorescent lighting provided illumination $12 \mathrm{~h}$ per day. A standard GLP diet and fresh water were provided ad libitum. Furthermore, all experiments were carried out under a blind protocol, and the effects were assessed by examiners who were completely unaware of the protocol. We certify that government regulations concerning the ethical use of animals were adhered to during this research.

\section{Drugs}

The pentadecapeptide BPC 157 (GEPPPGKPADDAGLV, M.W. 1419) (Diagen, Ljubljana, Slovenia) dissolved in $0.9 \% \mathrm{NaCl}$ was used in all experiments [1-11]. The peptide BPC 157 is part of the sequence of the human gastric juice protein BPC and is freely soluble in water and $0.9 \% \mathrm{NaCl}$ at $\mathrm{pH} 7.0$. BPC 157 was prepared as described previously with $99 \%$ high-pressure liquid chromatography (HPLC) purification, expressing 1-des-Gly peptide as an impurity [1-11]. 


\section{Surgery and spinal cord injury}

Deeply anesthetized (3\% isoflurane, ketamine $50 \mathrm{mg} / \mathrm{kg}$ b.w.) rats were subjected to laminectomy at lumbar level L2-L3, which corresponds to the sacrocaudal spinal cord (S2-Co1) as described previously [42]. A neurosurgical piston with a graduated force of $60-66 \mathrm{~g}$ was placed over the exposed dura and left for $60 \mathrm{~s}$ to induce a compression injury. After the piston was removed, the muscle and skin incisions were closed. A single injection (0.9\% NaCl $5 \mathrm{ml} / \mathrm{kg}$ b.w.; pentadecapeptide BPC 157 $200 \mu \mathrm{g} / \mathrm{kg}$ b.w. or $2 \mu \mathrm{g} / \mathrm{kg}$ b.w.) was administered intraperitoneally $10 \mathrm{~min}$ postinjury. Thereafter, the animals were returned to their cages in pairs, and food and water were provided ad libitum. According to previously assigned interval groups $(7,15,30,90,180$, and 360 days), the animals were sacrificed with an overdose of $3 \%$ isoflurane. To establish secondary spinal cord injury, four animals were sacrificed $10 \mathrm{~min}$ after spinal injury immediately prior to the administration of therapy. Four animals were subjected only to laminectomy without spinal cord injury and sacrificed after 360 days.

\section{Clinical evaluation}

Tail motor function was scored $8 \mathrm{~h}$ and $1,4,7,15,30$, 90,180 , and 360 days after injury (0-autotomy; $1-$ complete loss of tail function; 2-maximum elevation of $1 / 4$ of the tail length; $3-$ maximum elevation of $1 / 2$ of the tail length; 4-maximum elevation of $3 / 4$ of the tail length; 5-normal function). At the same intervals, the tails were observed for spasticity; after manual stimulation with the standardized stretch/rub maneuver, the tails were scored according to the Bennett scale [42]: 0normal phenotype; 1 -flaccid tail; 2-hypertonic flexor muscle with coiled and stiff tail; 3-hyperreflexia, e.g., coiling flexor spasm and clonus in response to light touch or stretch; and 4-hypertonic flexor and extensor muscles, clonus and hyperreflexia, the latter including a positive curling reaction.

\section{Electrophysiology recordings}

Before sacrifice, the animals from the 30-, 90-, 180-, and 360-day postspinal cord injury interval groups were placed in a wooden box with their tails exposed. Three pairs of monopolar needles were stabbed $3 \mathrm{~mm}$ deep into the tail 10,60, and $100 \mathrm{~mm}$ caudal to the tail base. Using a TECA 15 electromyography apparatus with a signal filter between $50 \mathrm{~Hz}$ and $5 \mathrm{kHz}$, voluntary muscle activity was recorded from the most caudal pair of electrodes, and the average motor unit potential (MUP) was recorded. Thereafter, the compound motor action potential (CMAP) was recorded from the same pair of electrodes after stimulating the first and second electrodes (a repetition of $1 \mathrm{~Hz}$ and a stimulus duration of $0.05 \mathrm{~ms}$ ). The amplitude, polyphasic changes, and the proximal and distal CMAP latencies were recorded, and the nerve conduction velocity was calculated according to previous studies $[41,43]$.

\section{Histology}

A 10-mm long piece of the spinal column (the L2-L3 vertebral body) and the surrounding muscle were collected from each sacrificed animal and fixed in $4 \%$ formaldehyde in phosphate buffer (pH 7.4). Upon fixation, the spinal cord was decalcinated, dehydrated in graded ethanol solutions, and embedded in paraffin. Serial $5-\mu \mathrm{m}$ crosssections were deparaffinated in xylene, rehydrated in graded ethanol solutions, and stained with hematoxylin/ eosin and toluidine blue (Kemica, Croatia). Part of the spinal cord gray and white matter was used for analysis under light microscopy (magnification $\times 300$ ). According to previous studies $[13,33]$, the intensity and distribution of the following pathological spinal cord changes were evaluated semiquantitatively $(0-$ no changes; 1 -small or focal changes; 2 -moderate changes; 3 -numerous confluent changes): (a) the hemorrhagic zone, (b) edema, (c) the loss of neurons in anterior horn and intermediate gray matter, (d) vacuoles, and (e) the loss of lateral and posterior spinal column tracts.

For peripheral nerve analysis, a 5-mm-long piece of tail $15 \mathrm{~mm}$ distal from the tail base was collected from each sacrificed animal, fixed in $4 \%$ formaldehyde in phosphate buffer ( $\mathrm{pH}$ 7.4), decalcinated, and impregnated with $1 \%$ osmium tetroxide for a few days. The specimens were dehydrated in graded ethanol solutions, embedded in paraffin, cut into 5 - $\mu \mathrm{m}$ sections, deparaffinated in xylene, rehydrated in graded ethanol solutions, and mounted on glass slides. Representative field images of four caudal nerves from each tail were taken using light microscopy (magnification $\times 500$ ) with a CCD camera using ISSA 3.1 software (VamStec, Zagreb) according to a previous study [41]. Axonal myelination was analyzed according to the following quantifications: (a) the total number of myelinated axons per $10,000 \mu \mathrm{m}^{2}$; (b) the number of myelinated axons with a diameter $\geq 7 \mu \mathrm{m}$ per $10,000 \mu \mathrm{m}^{2}$; and (c) the average axonal diameter.

\section{Statistical analyses}

Scoring data are expressed as the median, min, and max and were analyzed by Kruskal-Wallis ANOVA ( $P$ values $<0.05$ were considered significant) followed by the Mann-Whitney $U$ test $(P$ values $<0.025$ were considered significant) with Bonferroni correction; these tests are considered nonparametric alternatives to one-way ANOVA and Student's $t$ test. Numeric data are expressed as the mean \pm standard deviation $(\mathrm{SD})$ and were analyzed by one-way ANOVA followed by LSD test. The statistical program Statistica for Windows, ver. 
12.1 (StatSoft Inc. Tulsa, OK, USA) was used for statistical analysis. $P$ values $<0.05$ were considered significant.

\section{Results}

\section{Clinical examinations}

\section{Tail motor function score}

As expected, the tail motor function scores demonstrated persistent debilitation in the rats that underwent spinal cord injury and received saline postinjury.

In contrast, after initial disability, the rats that underwent spinal cord injury and received BPC 157 exhibited consistent improvement in motor function compared to that in the corresponding controls (Fig. 1). In particular, from day 180, autotomy was noted in the rats that underwent spinal cord injury but not in those that had been treated with BPC 157 (Fig. 2).

\section{Tail spasticity}

Interestingly, the development of spasticity began earlier in the rats that underwent spinal cord injury and had been treated with BPC 157 than in the corresponding controls. However, the controls exhibited sustained spasticity until the end of the experiment (day 360) while the BPC 157 rats exhibited resolved spasticity by day 15 (Fig. 3).

\section{Histology results}

Before the initiation of therapy, at $10 \mathrm{~min}$ after injury induction, a large hemorrhagic zone was present over the lateral and posterior white columns in all of the rats, but there were no changes in the gray matter. Notably, after the application of saline or BPC 157, the injury progression in the rats from the different experimental groups was fundamentally different.

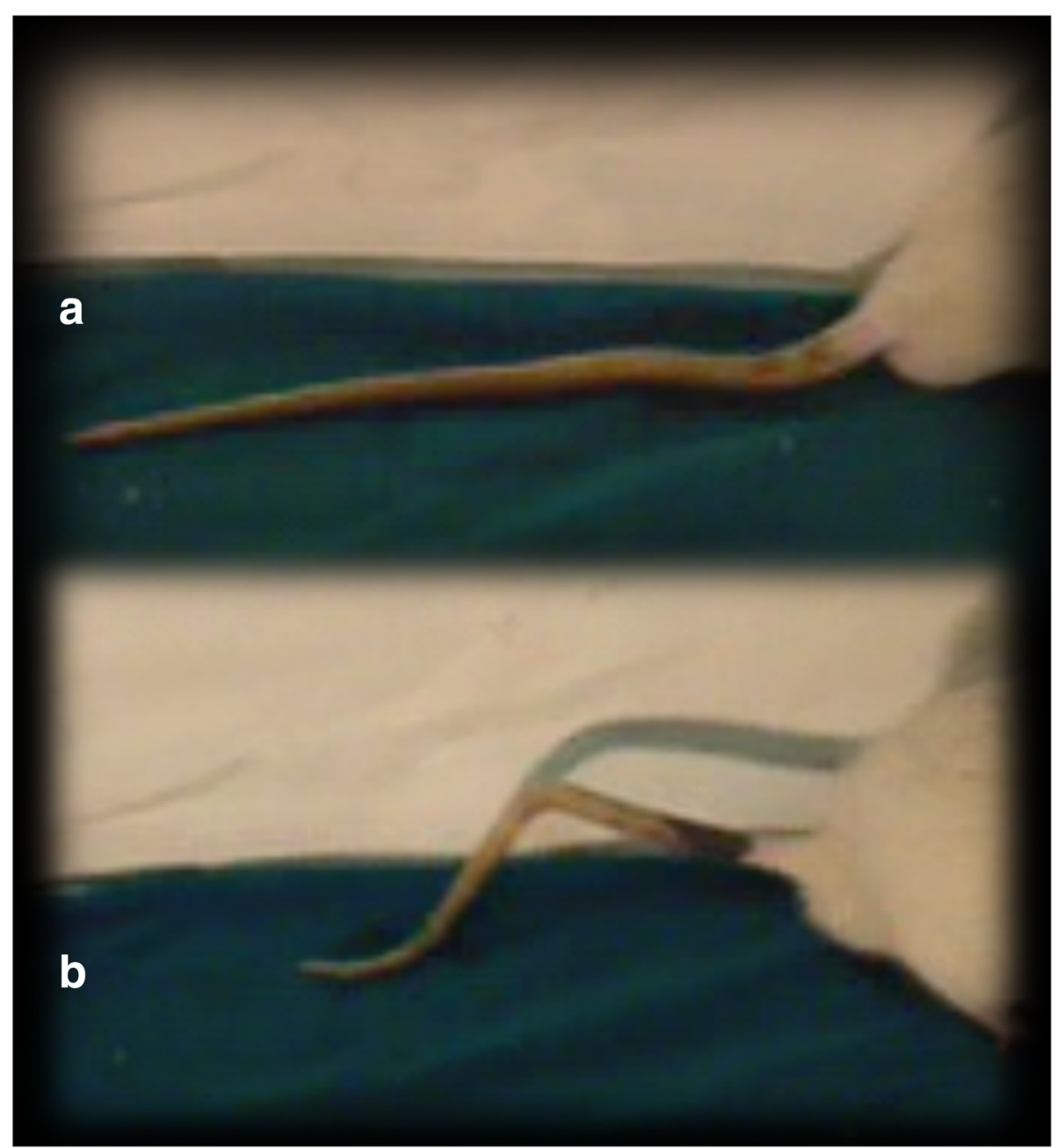

Fig. 1 Tail motor function $(\mathbf{a}, \mathbf{b})$ in rats that underwent spinal cord injury. Thirty days following injury. Debilitated rats underwent spinal cord injury that received saline post-injury (a). Contrarily, rats that had received BPC 157 (b) exhibit tail motor function rescue and consistently better motor function than the corresponding controls (a) 


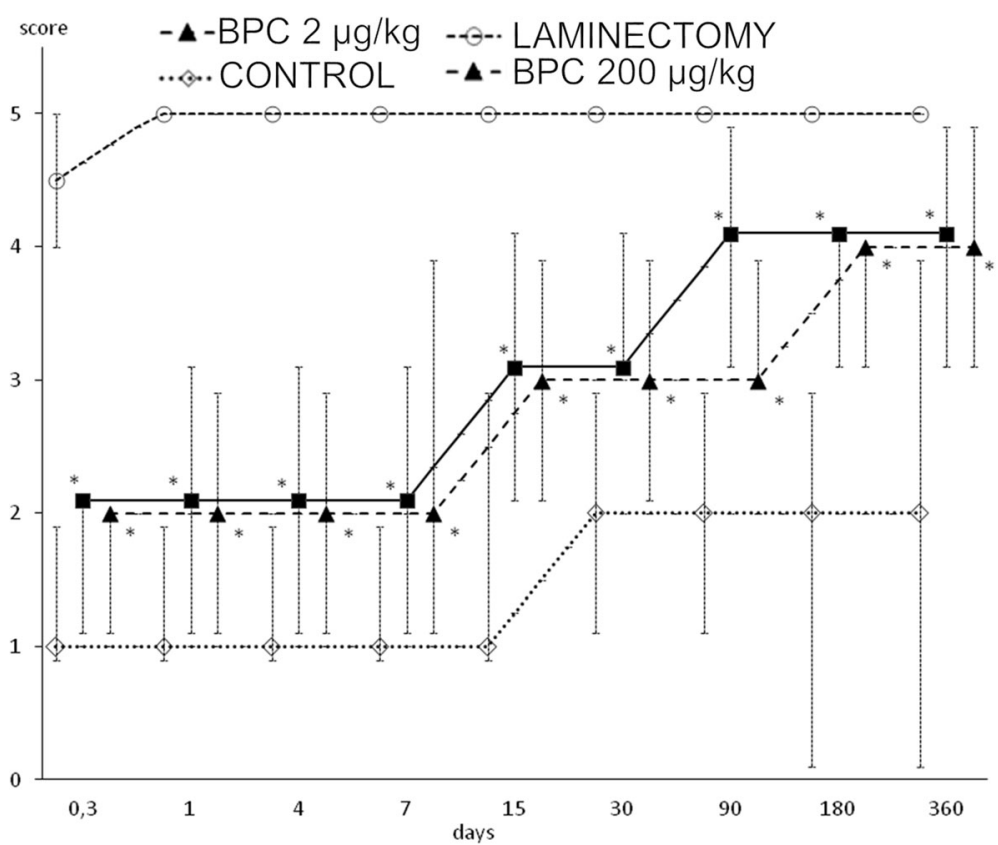

Fig. 2 In rats that underwent spinal cord injury, debilitated and rescued tail motor function (BPC 157 (200 or $2 \mu \mathrm{gg} / \mathrm{kg}$ ) or saline $5 \mathrm{ml} / \mathrm{kg}$ intraperitoneally at $10 \mathrm{~min}$ after injury) presented by tail motor function score. Mark presents median score, and vertical bars correspond to maximum and minimum score. ${ }^{*} P<0.025$ vs. control

Beginning on day 7 , vacuoles and the loss of posterior and lateral spinal column tracts were observed instead of hemorrhagic areas in all controls, disturbances that were largely counteracted in the BPC 157-treated rats (Table 1 and Fig. 4). Likewise, beginning on day 7 , the controls exhibited edema and the loss of neurons in the anterior horn and intermediate gray matter, disturbances that were largely counteracted the in BPC 157-treated rats (Table 2 and Fig. 5).

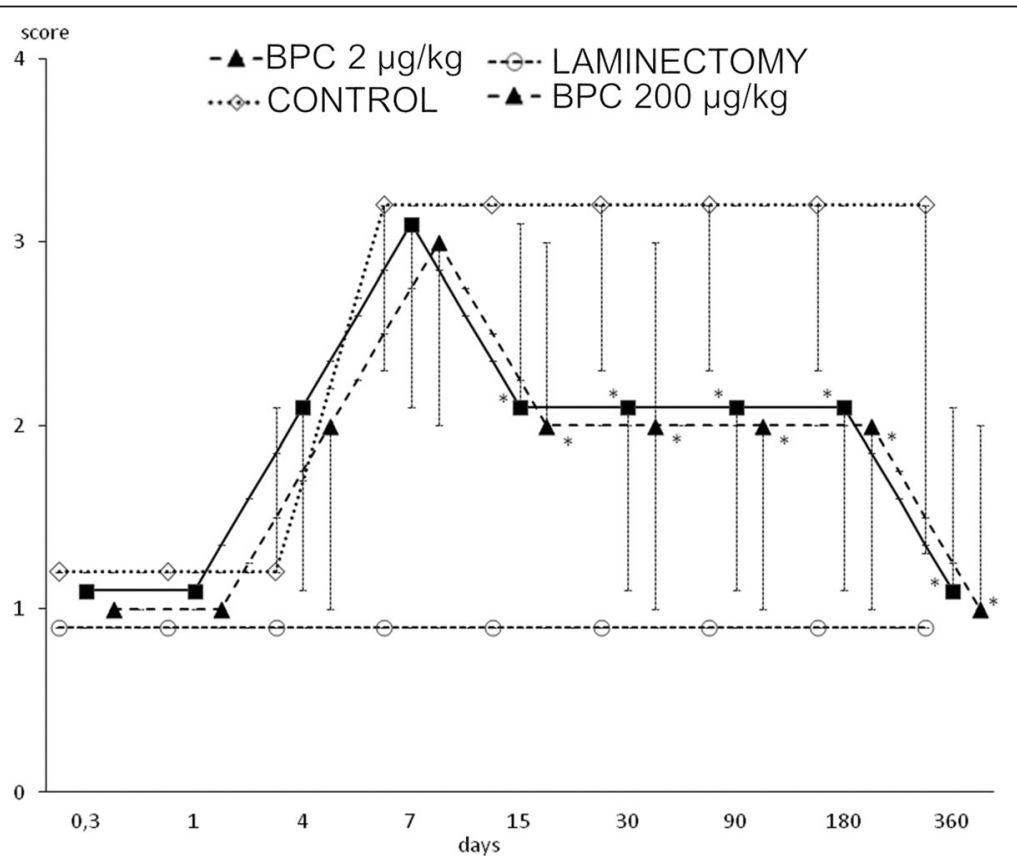

Fig. 3 In rats that underwent spinal cord injury, debilitated and rescued tail spasticity (BPC 157 (200 or 2 mg/kg) or saline 5 ml/kg intraperitoneally at 10 min after injury) according to Bennett scoring. Mark presents median, and vertical bars correspond to maximum and minimum score. ${ }^{*} P<0.025$ vs. control 
Table 1 Histology of lateral and posterior columns of spinal cord in 7 different time points, from 10 min till 360 days, after spinal cord injury

\begin{tabular}{|c|c|c|c|c|c|c|c|c|}
\hline \multirow[t]{2}{*}{ Treatment group } & & \multicolumn{7}{|c|}{ Time after spinal cord injury (min/med/max) } \\
\hline & & $10 \mathrm{~min}$. & 7 days & 15 days & 30 days & 90 days & 180 days & 360 days \\
\hline \multirow{3}{*}{$\begin{array}{l}\text { Control } \\
\text { saline } 5 \mathrm{ml} / \mathrm{kg} \text { b.w. i.p. }\end{array}$} & Hemorrhage & $2 / 2.5 / 3$ & $0 / 0 / 0$ & $0 / 0 / 0$ & $0 / 0 / 0$ & $0 / 0 / 0$ & $0 / 0 / 0$ & $0 / 0 / 0$ \\
\hline & Vacuoles & $0 / 0 / 0$ & $2 / 2.5 / 3$ & $1 / 3 / 3$ & $2 / 2 / 2$ & $2 / 2 / 2$ & $2 / 2.5 / 3$ & $2 / 2.5 / 3$ \\
\hline & Necrosis & 0/0/0 & $1 / 2.5 / 3$ & $2 / 3 / 3$ & $2 / 3 / 3$ & $2 / 3 / 3$ & $1 / 3 / 3$ & $1 / 3 / 3$ \\
\hline \multirow[t]{3}{*}{ Pentadecapeptide BPC 157200 g/kg b.w. i.p. } & Hemorrhage & $2 / 2.5 / 3$ & $0 / 0 / 0$ & $0 / 0 / 0$ & 0/0/0 & 0/0/0 & $0 / 0 / 0$ & $0 / 0 / 0$ \\
\hline & Vacuoles & 0/0/0 & $1 / 1 / 1^{*}$ & $1 / 1 / 1^{*}$ & $0 / 1 / 2^{*}$ & $1 / 1 / 1^{*}$ & $1 / 1 / 2^{*}$ & $1 / 2 / 2^{*}$ \\
\hline & Necrosis & 0/0/0 & $0 / 2 / 2$ & $0 / 0 / 2^{*}$ & $1 / 1 / 2^{*}$ & $0 / 0 / 1^{*}$ & $1 / 1 / 1^{*}$ & $0 / 0 / 1$ \\
\hline \multirow[t]{3}{*}{ Pentadecapeptide BPC 1572 mg/kg b.w. i.p. } & Hemorrhage & $2 / 2.5 / 3$ & 0/0/0 & $0 / 0 / 0$ & 0/0/0 & 0/0/0 & 0/0/0 & $0 / 0 / 0$ \\
\hline & Vacuoles & 0/0/0 & $1 / 1 / 1^{*}$ & $1 / 1 / 1^{*}$ & $0 / 1 / 2^{*}$ & $1 / 1 / 1^{*}$ & $1 / 1 / 2^{*}$ & $1 / 2 / 2^{*}$ \\
\hline & Necrosis & 0/0/0 & $0 / 2 / 2$ & $0 / 0 / 2^{*}$ & $1 / 1 / 2^{*}$ & $0 / 0 / 1^{*}$ & $1 / 1 / 1^{*}$ & $0 / 0 / 1$ \\
\hline \multirow[t]{3}{*}{ Laminectomy } & Hemorrhage & - & - & - & - & - & - & $0 / 0 / 0$ \\
\hline & Vacuoles & - & - & - & - & - & - & $0 / 0 / 0$ \\
\hline & Necrosis & - & - & - & - & - & - & $0 / 0 / 0$ \\
\hline
\end{tabular}

Semiquantitatively evaluated intensity of (a) hemorrhagic zone, (b) vacuoles, and (c) loss of tracts in lateral and posterior columns of spinal cord (0-no changes; 1 -small or focal changes; 2-moderate changes; 3-numerous confluent changes)

*Statistically significant difference BPC 157 groups vs control group, $P<0.025$

While the significance of this finding remains to be determined, it is probably worth mentioning that a decrease in the number of large myelinated axons in rat caudal nerves was observed in all animals until day 30 , with a markedly greater number in controls and fewer in injured rats that received BPC 157 treatment. Interestingly, after 180 days, recovery occurred, and the number of large myelinated axons in the controls reached that in the BPC 157-treated rats, and this finding persisted through the end of the experiment (Fig. 6).
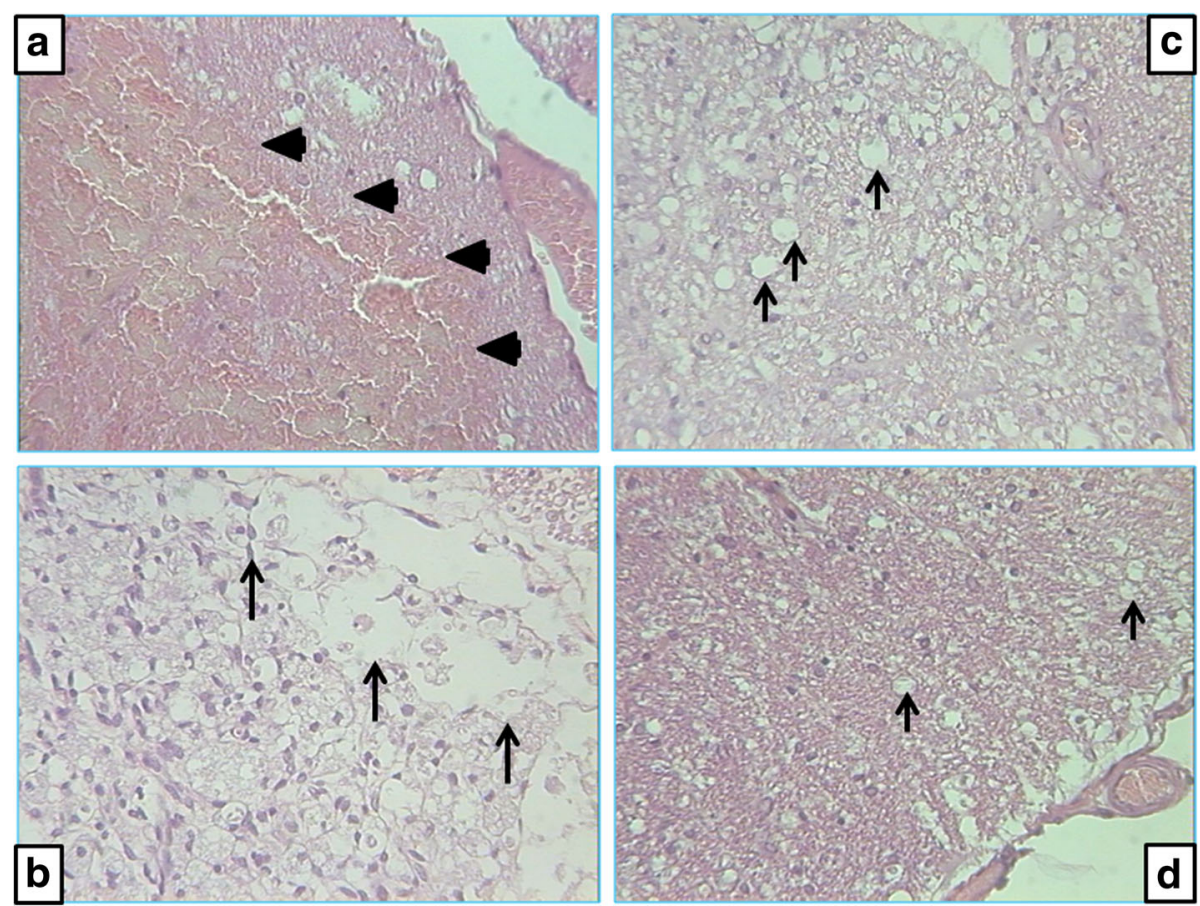

Fig. 4 Microscopic presentation of lateral columns of rat spinal cord at the lesion site. a Ten minutes after injury, all animals have numerous fields of hemorrhage — arrowheads. b-d Histology 30 days after injury: b control animals, numerous confluent vacuoles_arrows; c BPC $1572 \mu \mathrm{mg} / \mathrm{kg}$, few small vacuoles_arrows; d BPC $157200 \mu \mathrm{g} / \mathrm{kg}$, only occasionally small vacuoles_arrows. Staining H\&E, magnification $\times 300$ 
Table 2 Histology of anterior horn and intermediate gray matter of spinal cord in 7 different time points, from 10 min till 360 days, after spinal cord injury

\begin{tabular}{|c|c|c|c|c|c|c|c|c|}
\hline \multirow[t]{2}{*}{ Treatment group } & & \multicolumn{7}{|c|}{ Time after spinal cord injury (min/med/max) } \\
\hline & & $10 \mathrm{~min}$. & 7 days & 15 days & 30 days & 90 days & 180 days & 360 days \\
\hline \multirow{3}{*}{$\begin{array}{l}\text { Control } \\
\text { saline } 5 \mathrm{ml} / \mathrm{kg} \text { b.w. i.p. }\end{array}$} & Hemorrhage & $0 / 0 / 0$ & $0 / 0 / 0$ & $0 / 0 / 0$ & $0 / 0 / 0$ & $0 / 0 / 0$ & $0 / 0 / 0$ & $0 / 0 / 0$ \\
\hline & Edema & 0/0/0 & $1 / 1.5 / 2$ & $1 / 3 / 3$ & $3 / 3 / 3$ & $3 / 3 / 3$ & $3 / 3 / 3$ & $3 / 3 / 3$ \\
\hline & Necrosis & 0/0/0 & $1 / 1.5 / 2$ & $1 / 3 / 3$ & $3 / 3 / 3$ & $3 / 3 / 3$ & $3 / 3 / 3$ & $3 / 3 / 3$ \\
\hline \multirow[t]{3}{*}{ Pentadecapeptide BPC 157200 g/kg b.w. i.p. } & Hemorrhage & 0/0/0 & $0 / 0 / 0$ & $0 / 0 / 0$ & 0/0/0 & 0/0/0 & $0 / 0 / 0$ & $0 / 0 / 0$ \\
\hline & Edema & 0/0/0 & $0 / 1 / 1$ & $0 / 1 / 1^{*}$ & $0 / 1 / 3^{*}$ & $1 / 1 / 1^{*}$ & $1 / 1 / 1^{*}$ & $2 / 2 / 2^{*}$ \\
\hline & Necrosis & 0/0/0 & $0 / 1 / 1$ & $1 / 1 / 1$ & $0 / 1 / 3^{*}$ & $0 / 0 / 2^{*}$ & $3 / 3 / 3$ & $3 / 3 / 3$ \\
\hline \multirow[t]{3}{*}{ Pentadecapeptide BPC 1572 mg/kg b.w. i.p. } & Hemorrhage & 0/0/0 & 0/0/0 & 0/0/0 & 0/0/0 & 0/0/0 & 0/0/0 & $0 / 0 / 0$ \\
\hline & Edema & 0/0/0 & $0 / 1 / 1$ & $0 / 0 / 2^{*}$ & $1 / 2 / 2^{*}$ & $1 / 1 / 1^{*}$ & $1 / 1 / 1^{*}$ & $2 / 2 / 2^{*}$ \\
\hline & Necrosis & 0/0/0 & $1 / 1 / 1$ & $0 / 0 / 3$ & $1 / 2 / 2^{*}$ & $0 / 0 / 2^{*}$ & $3 / 3 / 3$ & $3 / 3 / 3$ \\
\hline \multirow[t]{3}{*}{ Laminectomy } & Hemorrhage & - & - & - & - & - & - & $0 / 0 / 0$ \\
\hline & Edema & - & - & - & - & - & - & $0 / 0 / 0$ \\
\hline & Necrosis & - & - & - & - & - & - & $0 / 0 / 0$ \\
\hline
\end{tabular}

Semiquantitatively evaluated intensity of (a) hemorrhagic zone, (b) edema, and (c) loss of neurons in anterior horn and intermediate gray matter of spinal cord (0-no changes; 1 -small or focal changes; 2-moderate changes; 3 -numerous confluent changes)

*Statistically significant difference between both pentadecapeptide BPC 157 groups and control group, $P<0.025$

\section{Electrophysiology results}

Based on a well-known phenomenon in peripheral nerve injury (i.e., as the number of preserved motoneurons decreases, the MUP (giant potential) in the tail muscle increases), it is conceivable that the BPC 157-treated rats that underwent spinal cord injury and were subjected to EMG recordings exhibited a markedly lower MUP in the tail muscle than that in the corresponding controls (Table 3). Consistently, the motor nerve conduction study confirmed the absence of demyelinated processes
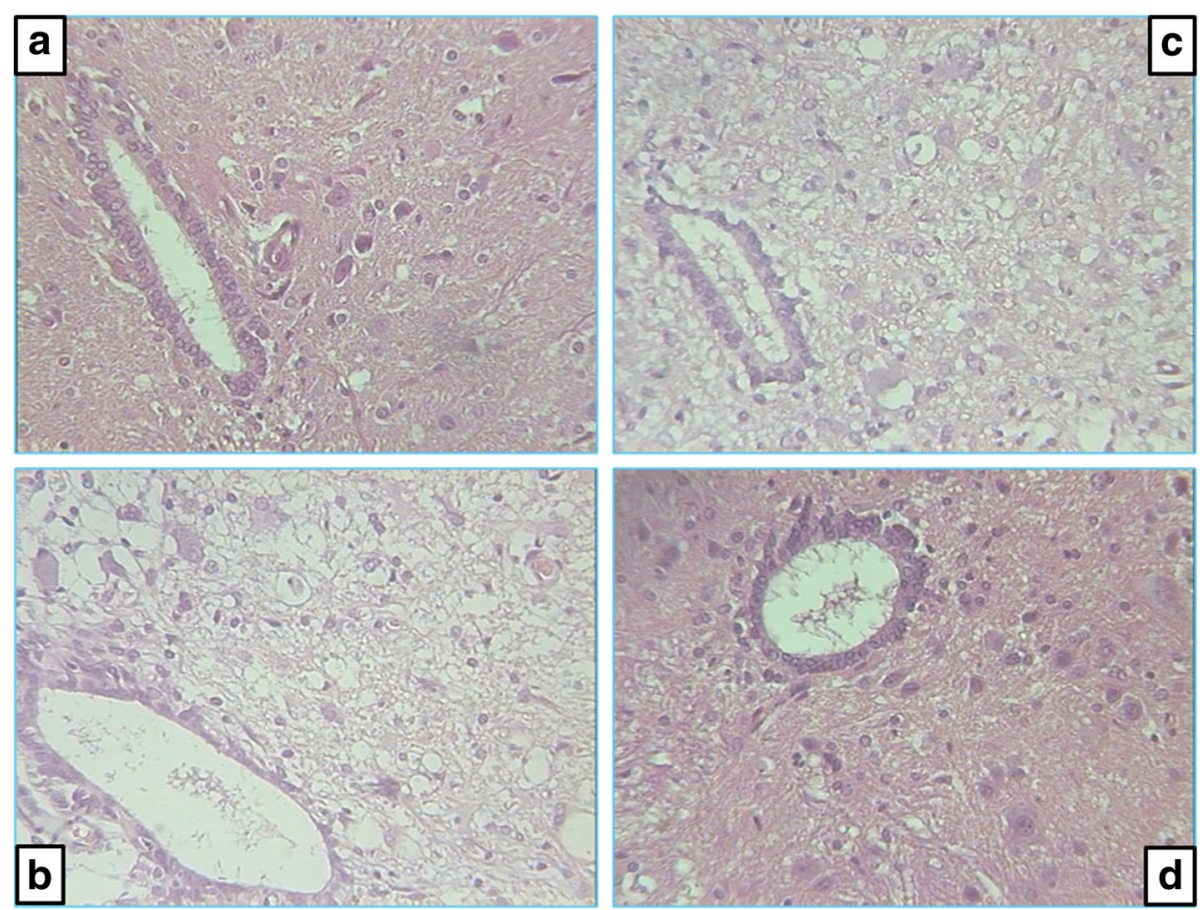

Fig. 5 Microscopic presentation of posttraumatic spinal cord changes in the intermediate gray matter at the lesion site. a Ten min after injury, all animals have no difference compared to healthy animals. b-d Histology 30 days after injury: b control animals, huge edema and loss of neurons; $\mathbf{c}$ BPC $1572 \mu \mathrm{g} /$ kg, minimal edema changes and occasionally loss of neurons; d BPC 157200 mg/kg, no difference to healthy animal. Staining H\&E, magnification $\times 300$ 


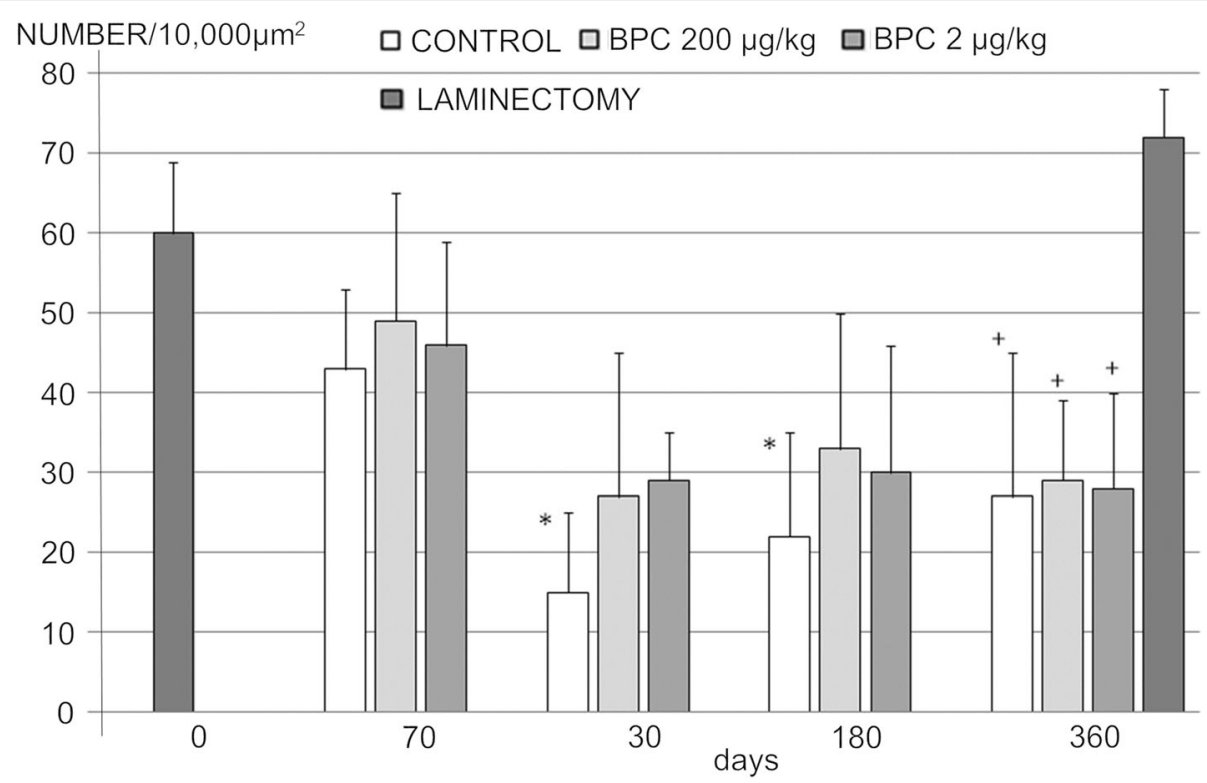

Fig. 6 A number of myelinated axons with diameter $\geq 7 \mu \mathrm{m}$ in rat caudal nerve per 10,000 $\mu \mathrm{m}^{2}$ in corresponding days. Columns present mean and vertical bars standard deviation. $P$ value ${ }^{*} P<0.05$ BPC 157 groups vs. saline. ${ }^{+} P<0.05$ saline and BPC 157 groups vs. laminectomy animals

in the tail caudal nerves after spinal cord injury (the CMAP showed normal biphasic potentials, similar amplitudes, and similar conduction velocities in all of the rats) (Table 4).

\section{Discussion}

This study attempted to demonstrate that the application of the stable gastric pentadecapeptide BPC 157 (by either of the used regimens) can improve the symptoms of spinal cord injury and lead to functional recovery in rats. In general, the one-time intraperitoneal application of the stable gastric pentadecapeptide BPC 157 is much like the engraftment of neural stem cells [16] or bone marrow stromal cells [17] into the lesion site. One should consider the primary phase lesion and hemorrhaging that results from mechanical damage during SCI as well as the secondary phase lesion that lasts several hours or even several months and is accompanied by edema, hemorrhage, inflammation, and cytotoxic edema [44-47] and may extend to the white matter area and lead to white matter degeneration and damage $[48,49]$. This substantiates the evidence that the spared white matter holds the key to the functional motor recovery of the hind limbs after SCI and is closely correlated with the functional restoration of the paralyzed hind limbs [50-52]. On the other hand, spontaneous and often substantial functional improvements [53-55] after partial lesioning of the spinal cord are associated with the spontaneous

Table 3 Voluntary electromyography (EMG) of rat segmental tail muscle, in 4 different time points, from 7 days till 360 days, after spinal cord injury

\begin{tabular}{|c|c|c|c|c|c|c|}
\hline \multirow[t]{3}{*}{ Group } & & \multicolumn{5}{|c|}{ Mean \pm SD } \\
\hline & & & \multicolumn{4}{|c|}{ Time of EMG recording after spinal cord injury } \\
\hline & & & 7 days & 30 days & 180 days & 360 days \\
\hline Healthy control & Amp./mV & $100 \pm 40$ & & & & \\
\hline Saline $5 \mathrm{ml} / \mathrm{kg}$ b.w. i.p. & Amp./mV & & $180 \pm 55$ & $370 \pm 52$ & $575 \pm 300$ & $460 \pm 175^{+}$ \\
\hline BPC 157200 mg/kg b.w. i.p. & Amp./mV & & $200 \pm 50$ & $200 \pm 80^{*}$ & $290 \pm 150^{*}$ & $300 \pm 65^{*+}$ \\
\hline BPC $1572 \mu \mathrm{g} / \mathrm{kg}$ b.w. i.p. & Amp./mV & & $210 \pm 25$ & $170 \pm 25^{*}$ & $270 \pm 110^{*}$ & $280 \pm 70^{*+}$ \\
\hline Laminectomy & Amp./mV & & & & & $125 \pm 30$ \\
\hline
\end{tabular}


Table 4 Stimulated electromyography (EMG) of rat segmental tail muscle, in 4 different time points, from 7 days till 360 days, after spinal cord injury

\begin{tabular}{|c|c|c|c|c|c|c|}
\hline \multirow[t]{3}{*}{ Group } & & \multicolumn{5}{|c|}{$\underline{\text { Mean } \pm \text { SD }}$} \\
\hline & & & \multicolumn{4}{|c|}{ Time of EMG recording after spinal cord injury } \\
\hline & & & 30 days & 90 days & 180 days & 360 days \\
\hline Healthy control & $\begin{array}{l}\text { Amp./mV } \\
\mathrm{NCV} / \mathrm{m} / \mathrm{s}\end{array}$ & $\begin{array}{l}3.0 \pm 0.8 \\
37 \pm 6\end{array}$ & & & & \\
\hline Saline $5 \mathrm{ml} / \mathrm{kg}$ b.w. i.p. & $\begin{array}{l}\mathrm{Amp} / \mathrm{mV} \\
\mathrm{NCV} / \mathrm{m} / \mathrm{s}\end{array}$ & & $\begin{array}{l}3.8 \pm 1.2 \\
38 \pm 14\end{array}$ & $\begin{array}{l}3.0 \pm 1.0 \\
36 \pm 12\end{array}$ & $\begin{array}{l}3.0 \pm 1.8 \\
35 \pm 11\end{array}$ & $\begin{array}{l}2.9 \pm 1.2 \\
36 \pm 10\end{array}$ \\
\hline BPC $157200 \mu \mathrm{g} / \mathrm{kg}$ b.w. i.p. & $\begin{array}{l}\mathrm{Amp} . / \mathrm{mV} \\
\mathrm{NCV} / \mathrm{m} / \mathrm{s}\end{array}$ & & $\begin{array}{l}3.3 \pm 1.3 \\
33 \pm 4\end{array}$ & $\begin{array}{l}4.3 \pm 3.0 \\
36 \pm 6\end{array}$ & $\begin{array}{l}2.8 \pm 2.2 \\
31 \pm 10\end{array}$ & $\begin{array}{l}2.6 \pm 1.5 \\
31 \pm 9\end{array}$ \\
\hline BPC $1572 \mu \mathrm{g} / \mathrm{kg}$ b.w.. i.p. & $\begin{array}{l}\text { Amp./mV } \\
\mathrm{NCV} / \mathrm{m} / \mathrm{s}\end{array}$ & & $\begin{array}{l}2.9 \pm 0.9 \\
37 \pm 8\end{array}$ & $\begin{array}{l}1.9 \pm 0.8 \\
37 \pm 7\end{array}$ & $\begin{array}{l}3.2 \pm 2.1 \\
30 \pm 9\end{array}$ & $\begin{array}{l}2.4 \pm 1.0 \\
31 \pm 8\end{array}$ \\
\hline Laminectomy & $\begin{array}{l}\text { Amp./mV } \\
\mathrm{NCV} / \mathrm{m} / \mathrm{s}\end{array}$ & & & & & $\begin{array}{l}3.3 \pm 1.3 \\
41 \pm 11\end{array}$ \\
\hline
\end{tabular}

Stimulated electromyography of rat segmental tail muscle. Compound muscle action potential amplitude (amp.) and nerve conduction velocity (NCV). Mean arithmetic mean, SD standard deviation. No statistical difference using one-way ANOVA analysis

sprouting of axons in the corticospinal tract [56-58] and the formation of neural circuits by spared spinal cord tissue [26]; these processes lead to partial functional recovery [59] or the formation of the neural fiber connection between the central pattern generator (CPG) and interneurons in the spinal cord, which can enable rhythmic movement [60-62].

Thus, to illustrate these combining points (i.e., [13, 44, 63]), considering that white matter injury is the major cause of functional loss after SCI $[45,52]$, it is important to note that cysts and the loss of axons instead of hemorrhagic areas were observed in the white matter in all of the controls beginning on day 7 and that the rats exhibited a tail motor score that persisted with only small improvements, sustained debilitation, sustained tail spasticity until the end of the experiment (day 360), a decrease in the number of large myelinated axons in the caudal nerve, a higher MUP (giant potential) in the tail muscle, and a group of atrophic fibers that likely represented a large unit that acquired many fibers through collateral reinnervation and then degenerated. Autotomy that occurs long after injury may appear as pain that occurs below the level of the injury (belowlevel pain) $[64,65]$, and the late spontaneous worsening may be the result of complete deafferentation of one or several spinal segments the stimulation of the nerve plexus, or dorsal root injury [66]. Together, these findings illustrate definitive spinal cord injury with very small spontaneous improvements in functional loss.

In contrast, it is possible that the administration of BPC 157 counteracts these disturbances to lead to considerable functional recovery. The vacuoles and the loss of axons in the white matter were largely counteracted in BPC 157-treated rats (Table 1 and Fig. 3). This result suggests that BPC 157-treated rats exhibit continual improvement in motor function even before tissue recovery, as observed by microscopy assessment. The resolution of spasticity by day 15 (Fig. 2) suggests that BPC 157 administration prevents the chain of events after spinal cord injury that is mediated by the loss of local segmental inhibition and/or by an increased sensory afferent drive that results in the exacerbation of $\alpha$ motoneuron activity [66]. These findings substantiate the number of large myelinated axons in the caudal nerve and the lower MUP in the tail muscle.

Likewise, autotomy was completely prevented, much like in a previous study that showed recovery in BPC 157-treated rats that underwent traumatic nerve injury [41]; this suggests the counteraction of the chain of events that otherwise leads to painful sensations and refers to denervated regions and the preservation of one or more spinal segments [41].

It is possible that BPC 157 may affect voltage-gated sodium channels (VGSCs), which play a major role in the generation and propagation of action potentials in primary afferents [67].

The abnormal processing of sensory inputs in the CNS [68]. Moreover, evidence that the compromised white matter integrity of specific spinal pathways has been linked to clinical disability [69-71], and cortical reorganization [72] should be considered in relation to the pleiotropic beneficial effect of BPC 157 administration observed in distinctive brain areas and lesions [32-40]. These beneficial effects include the counteractions of traumatic brain injury and severe encephalopathies after NSAID overdose, insulin overdose, magnesium overdose, and exposure to the neurotoxin cuprizone in a rat model of multiple sclerosis [33-41]. These beneficial effects may be due to the formation of detour circuits-which encompass spared tissue surrounding the lesion-and could 
reconnect locomotor circuits [69], thus enabling afferent inputs to be processed and conveyed to the cortex [73] and improving spinal reflexes, even below the injury [74].

Much like in the rats that underwent spinal cord injury recovery, rats with other disorders that are treated with BPC 157 maintain functional abilities that are otherwise impaired; for example, consciousness is maintained after brain trauma, and BPC 157 counteracts seizures, catalepsy akinesia, and severe muscle weakness [33-41, 75, 76]. The effect of BPC 157 on muscle function is combined with the counteraction of increased levels of pro-inflammatory and pro-cachectic cytokines and of downstream pathways to abolish muscle cachexia [2]. Likewise, BPC 157 ameliorates healing and recovers the impaired function of severely injured muscles that otherwise fail to spontaneously heal and plays a role after complete transection, crush, and denervation injuries [77-80] and after succinylcholine intramuscular application, muscle lesion, neuromuscular junction failure, fasciculations, paralysis, and hyperalgesia [81]. Likewise, given that the gray matter is particularly vulnerable during the primary phase [44, 63], we should note that, from day 7 , the controls presented with edema and the loss of motoneurons in the gray matter, disturbances that were largely counteracted in BPC 157-treated rats (Table 2 and Fig. 4).

In summary, this effect may be the cause or a consequence of the beneficial effects of BPC 157 on related disturbances [1-11]. As demonstrated, BPC 157 counteracts free radical formation and free radical-induced lesions $[32,82-84]$. An interesting point would be the use of the same dose range in BPC 157 studies [1-11]. Finally, further studies should clarify the molecular pathways involved and extend the one-time application (much like the engraftment of neural stem cells [16] or bone marrow stromal cells [17] into the lesion site) to the continuous application for the recovery of pre-existing spinal cord injury.

In conclusion, this manuscript tried to prove the therapeutic effects of BPC 157 in spinal cord injury using a rat model. Spinal cord injury recovery was achieved in BPC 157-treated rats, meaning that this therapy affects the acute, subacute, subchronic, and chronic stages of the secondary injury phase. Thus, despite the limitations of rat studies, the results showed that treatment with BPC 157 led to the recovery of tail function and the resolution of spasticity and improved the neurologic recovery; thus, BPC 157 may represent a potential therapy for spinal cord injury.

\footnotetext{
Abbreviations

CMAP: Compound motor action potential; CNS: Central nervous system; ECM: Cone-extracellular matrix; egr-1 gene : Early growth response-1 gene; EMG: Electromyography; FAK: Focal adhesion kinase; GLP: Good laboratory practice; HNE: 4-Hydroxynonenal; HPLC: High-pressure liquid

chromatography; JAK-2: Janus kinase 2; LD1: Lethal dose 1; LTB4: Leukotriene B4; MPO: Myeloperoxidase; MPTP: 1-Methyl-4-phenyl-1,2,3,6-

tetrahydropyridine; MUP: Motor unit potential; naB2: Nerve growth factor 1-A
}

binding protein-2; NSAIDs: Non-steroid anti-inflammatory drugs; SCl: Spinal cord injury; TXB2: Thromboxane B2

\section{Acknowledgements}

Not applicable

\section{Authors' contributions}

$D P, D K, D D, G B, S S$, and PS performed the experiments. DP, DK, VB, NS, DD, $E E$, GB, SS, and PS collected and analyzed data. DP, DK, GB, SS, and PS wrote the manuscript. All authors read and approved the final manuscript.

\section{Funding}

This research was supported by the Ministry of Science, Education and Sports, Republic of Croatia (grant number 108-1083570-3635). There was no role of the funding body in the design of the study and collection, analysis, and interpretation of data and in writing the manuscript should be declared.

\section{Availability of data and materials}

All data are included in the manuscript.

Ethics approval and consent to participate

Approved by Ethics Committee, School of Medicine, University of Zagreb, 04 1121-2006 for experiments with rats.

Consent for publication

Not applicable

Competing interests

The authors declare that they have no competing interests.

\section{Author details}

${ }^{1}$ Department of Pharmacology, School of Medicine, University of Zagreb, Salata 11, P.O. Box 916, 10000 Zagreb, Croatia. ${ }^{2}$ Department of Pathology, School of Medicine, University of Zagreb, Salata 9, 10000 Zagreb, Croatia.

Received: 10 January 2019 Accepted: 18 June 2019

Published online: 02 July 2019

\section{References}

1. Seiwerth S, Rucman R, Turkovic B, Sever M, Klicek R, Radic B, et al. BPC 157 and standard angiogenic growth factors. Gastrointestinal tract healing, lessons from tendon, ligament, muscle and bone healing. Curr Pharm Des. 2018;24(18):1972-89.

2. Kang EA, Han YM, An JM, Park YJ, Sikiric P, Kim DH, et al. BPC157 as potential agent rescuing from cancer cachexia. Curr Pharm Des. 2018;24(18): 1947-56.

3. Sikiric P, Rucman R, Turkovic B, Sever M, Klicek R, Radic B, et al. Novel cytoprotective mediator, stable gastric pentadecapeptide BPC 157. Vascular recruitment and gastrointestinal tract healing. Curr Pharm Des. 2018;24(18): 1990-2001.

4. Sikiric P, Seiwerth S, Rucman R, Drmic D, Stupnisek M, Kokot A, et al. Stress in gastrointestinal tract and stable gastric pentadecapeptide BPC 157. Finally, do we have a solution? Curr Pharm Des. 2017;23(27):4012-28.

5. Sikiric $P$, Seiwerth $S$, Rucman $R$, Kolenc $D$, Vuletic LB, Drmic $D$, et al. Braingut axis and pentadecapeptide BPC 157: theoretical and practical implications. Curr Neuropharmacol. 2016;14(8):857-65.

6. Seiwerth S, Brcic L, Vuletic LB, Kolenc D, Aralica G, Misic M, et al. BPC 157 and blood vessels. Curr Pharm Des. 2014;20(7):1121-5.

7. Sikiric P, Seiwerth S, Rucman R, Turkovic B, Rokotov DS, Brcic L, et al. Stable gastric pentadecapeptide BPC 157-NO-system relation. Curr Pharm Des. 2014;20(7):1126-35.

8. Sikiric P, Seiwerth S, Rucman R, Turkovic B, Rokotov DS, Brcic L, et al. Toxicity by NSAIDs. Counteraction by stable gastric pentadecapeptide BPC 157. Curr Pharm Des. 2013;19(1):76-83.

9. Sikiric P, Seiwerth S, Rucman R, Turkovic B, Rokotov DS, Brcic L, et al. Focus on ulcerative colitis: stable gastric pentadecapeptide BPC 157. Curr Med Chem. 2012:19(1):126-32.

10. Sikiric P, Seiwerth S, Rucman R, Turkovic B, Rokotov DS, Brcic L, et al. Stable gastric pentadecapeptide BPC 157: novel therapy in gastrointestinal tract. Curr Pharm Des. 2011;17(16):1612-32. 
11. Sikiric P, Seiwerth S, Brcic L, Sever M, Klicek R, Radic B, et al. Revised Robert's cytoprotection and adaptive cytoprotection and stable gastric pentadecapeptide BPC 157. Possible significance and implications for novel mediator. Curr Pharm Des. 2010;16(10):1224-34.

12. Kjell J, Olson L. Rat models of spinal cord injury: from pathology to potential therapies. Dis Mod Mech. 2016;9:1125-37.

13. Ek CJ, Habgood MD, Dennis R, Dziegielewska KM, Mallard C, Wheaton B, et al. Pathological changes in the white matter after spinal contusion injury in the rat. PLoS One. 2012;7(8):e43484.

14. Abrams MB, Nilsson I, Lewandowski SA, Kjell J, Codeluppi S, Olson L, et al. Imatinib enhances functional outcome after spinal cord injury. PLoS One. 2012;7(6):e38760.

15. Kopp MA, Liebscher T, Niedeggen A, Laufer S, Brommer B, Jungehulsing GJ, et al. Small-molecule-induced Rho-inhibition: NSAIDs after spinal cord injury. Cell Tissue Res. 2012;349(1):119-32.

16. Lu P, Wang Y, Graham L, McHale K, Gao M, Wu D, et al. Long-distance growth and connectivity of neural stem cells after severe spinal cord injury. Cell. 2012;150(6):1264-73.

17. Ritfeld GJ, Nandoe Tewarie RD, Vajn K, Rahiem ST, Hurtado A, Wendell DF, et al. Bone marrow stromal cell-mediated tissue sparing enhances functional repair after spinal cord contusion in adult rats. Cell Transplant. 2012;21(7):1561-75.

18. Sharp KG, Yee KM, Steward O. A re-assessment of treatment with a tyrosine kinase inhibitor (imatinib) on tissue sparing and functional recovery after spinal cord injury. Exp Neurol. 2014;254:1-11.

19. Sharp KG, Yee KM, Stiles TL, Aguilar RM, Steward O. A re-assessment of the effects of treatment with a non-steroidal anti-inflammatory (ibuprofen) on promoting axon regeneration via RhoA inhibition after spinal cord injury. Exp Neurol. 2013;248:321-37.

20. Hofstetter CP, Schwarz EJ, Hess D, Widenfalk J, El Manira A, Prockop DJ, et al. Marrow stromal cells form guiding strands in the injured spinal cord and promote recovery. Proc Natl Acad Sci U S A. 2002;99:2199-204.

21. Nandoe Tewarie RDS, Hurtado A, Ritfeld GJ, Rahiem ST, Wendell DF, Barroso MMS, et al. Bone marrow stromal cells elicit tissue sparing after acute but not delayed transplantation into the contused adult rat thoracic spinal cord. J Neurotrauma. 2009;26(12):2313-22.

22. Sharp KG, Yee KM, Steward O. A re-assessment of long distance growth and connectivity of neural stem cells after severe spinal cord injury. Exp Neurol. 2014;257:186-204.

23. Lu P, Graham L, Wang Y, Wu D, Tuszynski M. Promotion of survival and differentiation of neural stem cells with fibrin and growth factor cocktails after severe spinal cord injury. J Vis Exp. 2014;27(89):e50641. https://doi.org/ $10.3791 / 50641$

24. Ritfeld GJ, Nandoe Tewarie RD, Rahiem ST, Hurtado A, Roos RA, Grotenhuis A, et al. Reducing macrophages to improve bone marrow stromal cell survival in the contused spinal cord. Neuroreport. 2010;21(3):221-6.

25. Chen K, Marsh BC, Cowan M, Al'Joboori YD, Gigout S, Smith CC, et al. Sequential therapy of anti-Nogo-A antibody treatment and treadmill training leads to cumulative improvements after spinal cord injury in rats. Exp Neurol. 2017;292:135-44.

26. Filli L, Schwab ME. Structural and functional reorganization of propriospinal connections promotes functional recovery after spinal cord injury. Neural Regen Res. 2015;10(4):509-13.

27. Hsieh M-J, Liu H-T, Wang C-N, Huang H-Y, Lin Y, Ko Y-S, et al. Therapeutic potential of pro-angiogenic BPC157 is associated with VEGFR2 activation and up-regulation. J Mol Med. 2017;95:323-33.

28. Chang C-H, Tsai W-C, Lin M-S, Hsu Y-H, Pang J-HS. The promoting effect of pentadecapeptide BPC 157 on tendon healing involves tendon outgrowth, cell survival, and cell migration. J Appl Physiol. 2011;110:774-80.

29. Chang C-H, Tsai W-C, Hsu Y-H, Pang J-HS. Pentadecapeptide BPC 157 enhances the growth hormone receptor expression in tendon fibroblasts. Molecules. 2014;19:19066-77.

30. Huang T, Zhang K, Sun L, Xue X, Zhang C, Shu Z, et al. Body protective compound-157 enhances alkali-burn wound healing in vivo and promotes proliferation, migration, and angiogenesis in vitro. Drug Des Devel Ther. 2015;9:2485-99.

31. Tkalčević VI, Čužić S, Brajša K, Mildner B, Bokulić A, Šitum K, et al. Enhancement by PL 14736 of granulation and collagen organization in healing wounds and the potential role of egr-1 expression. Eur J Pharmacol. 2007;570:212-21.

32. Vukojević J, Siroglavić M, Kašnik K, Kralj T, Stanćić D, Kokot A, et al. Rat inferior caval vein (ICV) ligature and particular new insights with the stable gastric pentadecapeptide BPC 157. Vasc Pharmacol. 2018;106:54-66.
33. Tudor M, Jandric I, Marovic A, Gjurasin M, Perovic D, Radic B, et al. Traumatic brain injury in mice and pentadecapeptide BPC 157 effect. Regul Pept. 2010; 160(1-3):26-32.

34. Drmic D, Kolenc D, llic S, Bauk L, Sever M, Zenko Sever A, et al. Celecoxibinduced gastrointestinal, liver and brain lesions in rats, counteraction by BPC 157 or L-arginine, aggravation by L-NAME. World J Gastroenterol. 2017; 23(29):5304-12.

35. Ilic S, Drmic D, Franjic S, Kolenc D, Coric M, Brcic L, et al. Pentadecapeptide BPC 157 and its effects on a NSAID toxicity model: diclofenac-induced gastrointestinal, liver, and encephalopathy lesions. Life Sci. 2011;88(11-12):535-42.

36. Ilic S, Drmic D, Zarkovic K, Kolenc D, Brcic L, Radic B, et al. Ibuprofen hepatic encephalopathy, hepatomegaly, gastric lesion and gastric pentadecapeptide BPC 157 in rats. Eur J Pharmacol. 201 1;667(1-3):322-9.

37. Ilic S, Drmic D, Zarkovic K, Kolenc D, Coric M, Brcic L, et al. High hepatotoxic dose of paracetamol produces generalized convulsions and brain damage in rats. A counteraction with the stable gastric pentadecapeptide BPC 157 (PL 14736). J Physiol Pharmacol. 2010;61(2):241-50.

38. Ilic S, Brcic I, Mester M, Filipovic M, Sever M, Klicek R, et al. Over-dose insulin and stable gastric pentadecapeptide BPC 157. Attenuated gastric ulcers, seizures, brain lesions, hepatomegaly, fatty liver, breakdown of liver glycogen, profound hypoglycemia and calcification in rats. J Physiol Pharmacol. 2009;60(Suppl 7):107-14.

39. Klicek R, Kolenc D, Suran J, Drmic D, Brcic L, Aralica G, et al. Stable gastric pentadecapeptide BPC 157 heals cysteamine-colitis and colon-colonanastomosis and counteracts cuprizone brain injuries and motor disability. J Physiol Pharmacol. 2013;64(5):597-612.

40. Medvidovic-Grubisic M, Stambolija V, Kolenc D, Katancic J, Murselovic T, Plestina-Borjan I, et al. Hypermagnesemia disturbances in rats, NO-related: pentadecapeptide BPC 157 abrogates, L-NAME and L-arginine worsen. Inflammopharmacology. 2017;25(4):439-49.

41. Gjurasin M, Miklic P, Zupancic B, Perovic D, Zarkovic K, Brcic L, et al. Peptide therapy with pentadecapeptide BPC 157 in traumatic nerve injury. Regul Pept. 2010;160(1-3):33-41.

42. Bennett DJ, Gorassini M, Fouad K, Sanelli L, Han Y, Cheng J. Spasticity in rats with sacral spinal cord injury. J Neurotrauma. 1999;16(1):69-84.

43. Tanimoto K, Khoury B, Feng K, Cavanaugh JM. Evaluation of sciatic nerve function after ultrasonic and electrocautery muscle dissection: an electromyographic study. J Neurol Surg A Cent Eur Neurosurg. 2015;76(2): 93-8.

44. Song W, Song G, Zhao C, Li X, Pei X, Zhao W, et al. Testing pathological variation of white matter tract in adult rats after severe spinal cord injury with MRI. Biomed Res Int. 2018;2018:4068156.

45. Kozlowski P, Raj D, Liu J, Lam C, Yung AC, Tetzlaff W. Characterizing white matter damage in rat spinal cord with quantitative MRI and histology. J Neurotrauma. 2008;25(6):653-76

46. Borgens RB, Liu-Snyder P. Understanding secondary injury. Q Rev Biol. 2012; 87(2):89-127.

47. Donnelly J, Popovich PG. Inflammation and its role in neuroprotection, axonal regeneration and functional recovery after spinal cord injury. Exp Neurol. 2008;209(2):378-88.

48. Wu J, Stoica BA, Dinizo M, Pajoohesh-Ganji A, Piao C, Faden Al. Delayed cell cycle pathway modulation facilitates recovery after spinal cord injury. Cell Cycle. 2012;11(9):1782-95.

49. Wu W, Wang P, Cheng JX, Xu XM. Assessment of white matter loss using bond-selective photoacoustic imaging in a rat model of contusive spinal cord injury. J Neurotrauma. 2014;31(24):1998-2002.

50. Schucht P, Raineteau O, Schwab OE, Fouad K. Anatomical correlates of locomotor recovery following dorsal and ventral lesions of the rat spinal cord. Exp Neurol. 2002;176(1):143-53.

51. Basso DM, Beattie MS, Bresnahan JC. Graded histological and locomotor outcomes after spinal cord contusion using the NYU weight-drop device versus transection. Exp Neurol. 1996;139(2):244-56.

52. Ward RE, Huang W, Kostusiak M, Pallier PN, Michael-Titus AT, Priestley JV. A characterization of white matter pathology following spinal cord compression injury in the rat. Neuroscience. 2014;260:227-39.

53. Rossignol S, Drew T, Brustein E, Jiang W. Locomotor performance and adaptation after partial or complete spinal cord lesions in the cat. Prog Brain Res. 1999;123:349-65.

54. Wernig A, Müller S. Laufband locomotion with body weight support improved walking in persons with severe spinal cord injuries. Paraplegia. 1992;30(4):229-38 
55. Dietz V, Wirz M, Curt A, Colombo G. Locomotor pattern in paraplegic patients: training effects and recovery of spinal cord function. Spinal Cord. 1998;36(6):380-90.

56. Li X, Yang Z, Zhang A, Wang T, Chen W. Repair of thoracic spinal cord injury by chitosan tube implantation in adult rats. Biomaterials. 2009;30(6):1121-32.

57. Fouad K, Pedersen V, Schwab ME, Brösamle C. Cervical sprouting of corticospinal fibers after thoracic spinal cord injury accompanies shifts in evoked motor responses. Curr Biol. 2001;11(22):1766-70.

58. Raineteau O, Schwab ME. Plasticity of motor systems after incomplete spinal cord injury. Nat Rev Neurosci. 2001;2(4):263-73.

59. Rosenzweig ES, Courtine G, Jindrich DL, Brock JH, Ferguson AR, Strand SC, et al. Extensive spontaneous plasticity of corticospinal projections after primate spinal cord injury. Nat Neurosci. 2010;13(12):1505-10.

60. Cazalets JR, Borde M, Clarac F. Localization and organization of the central pattern generator for hindlimb locomotion in newborn rat. J Neurosci. 1995; 15(7 Pt 1):4943-51.

61. Kremer $\mathrm{E}$, Lev-Toy A. Localization of the spinal network associated with generation of hindlimb locomotion in the neonatal rat and organization of its transverse coupling system. J Neurophysiol. 1997;77(3):1155-70.

62. Chau C, Rossignol S. Noradrenergic agonists and locomotor training affect locomotor recovery after cord transection in adult cats. Brain Res Bull. 1993; 30(3-4):387-93.

63. Hausmann ON. Post-traumatic inflammation following spinal cord injury. Spinal Cord. 2003;41(7):369-78.

64. Wieseler J, Ellis AL, McFadden A, Brown K, Starnes C, Maier SF, et al. Below level central pain induced by discrete dorsal spinal cord injury. J Neurotrauma. 2010;27(9):1697-707.

65. Zimmermann M. Pathobiology of neuropathic pain. Eur J Pharmacol. 2001; 429:23-37.

66. Kupcova Skalnikova H, Navarro R, Marsala S, Hrabakova R, Vodicka P, Gadher SJ, et al. Signaling proteins in spinal parenchyma and dorsal root ganglion in rat with spinal injury-induced spasticity. J Proteome. 2013;91:41-57.

67. Persson AK, Thun J, Xu XJ, Wiesenfeld-Hallin Z, Ström M, Devor M, et al. Autotomy behavior correlates with the DRG and spinal expression of sodium channels in inbred mouse strains. Brain Res. 2009;1285:1-13.

68. Zhang SH, Blech-Hermoni Y, Faravelli L, Seltzer Z. Ralfinamide administered orally before hindpaw neurectomy or postoperatively provided long-lasting suppression of spontaneous neuropathic pain-related behavior in the rat. Pain. 2008;139(2):293-305.

69. Freund P, Curt A, Friston K, Thompson A. Tracking changes following spinal cord injury: insights from neuroimaging. Neuroscientist. 2013;19(2):116-28.

70. Cohen-Adad J, El Mendili MM, Lehéricy S, Pradat PF, Blancho S, Rossignol S, et al. Demyelination and degeneration in the injured human spinal cord detected with diffusion and magnetization transfer MRI. Neuroimage. 2011; 55(3):1024-33.

71. Petersen JA, Wilm BJ, von Meyenburg J, Schubert M, Seifert B, Najafi Y, et al. Chronic cervical spinal cord injury: DTI correlates with clinical and electrophysiological measures. J Neurotrauma. 2012;29(8):1556-66

72. Freund P, Wheeler-Kingshott CA, Nagy Z, Gorgoraptis N, Weiskopf N, Friston $\mathrm{K}$, et al. Axonal integrity predicts cortical reorganisation following cervical injury. J Neurol Neurosurg Psychiatry. 2012;83(6):629-37.

73. Courtine G, Song B, Roy RR, Zhong H, Herrmann JE, Ao Y, et al. Recovery of supraspinal control of stepping via indirect propriospinal relay connections after spinal cord injury. Nat Med. 2008;14:69-74.

74. Hubli M, Dietz V, Bolliger M. Spinal reflex activity: a marker for neuronal functionality after spinal cord injury. Neurorehabil Neural Repair. 2012;26:188-96.

75. Jelovac N, Sikiric P, Rucman R, Petek M, Marovic A, Perovic D, et al. Pentadecapeptide BPC 157 attenuates disturbances induced by neuroleptics: the effect on catalepsy and gastric ulcers in mice and rats. Eur J Pharmacol. 1999;379(1):19-31.

76. Sikiric P, Marovic A, Matoz W, Anic T, Buljat G, Mikus D, et al. A behavioural study of the effect of pentadecapeptide BPC 157 in Parkinson's disease models in mice and gastric lesions induced by 1-methyl-4-phenyl-1,2,3,6tetrahydrophyridine. J Physiol Paris. 1999;93(6):505-12.

77. Staresinic M, Petrovic I, Novinscak T, Jukic I, Pevec D, Suknaic S, et al. Effective therapy of transected quadriceps muscle in rat: gastric pentadecapeptide BPC 157. J Orthop Res. 2006;24:1109-17.

78. Novinscak T, Brcic L, Staresinic M, Jukic I, Radic B, Pevec D, et al. Gastric pentadecapeptide BPC 157 as an effective therapy for muscle crush injury in the rat. Surg Today. 2008:38:716-25.
79. Pevec D, Novinscak T, Brcic L, Sipos K, Jukic I, Staresinic M, et al. Impact of pentadecapeptide BPC 157 on muscle healing impaired by systemic corticosteroid application. Med Sci Monit. 2010;16:81-8.

80. Mihovil I, Radic B, Brcic I, Drmic D, Vukoja I, Boban Blagaic A, et al. Beneficial effect of pentadecapeptide BPC 157 on denervated muscle in rats. Int Congress Myol Myol. 2008;431:26-30.

81. Stambolija V, Stambolija TP, Holjevac JK, Murselovic T, Radonic J, Duzel V, et al. BPC 157: the counteraction of succinylcholine, hyperkalemia, and arrhythmias. Eur J Pharmacol. 2016;781:83-91.

82. Duzel A, Vlainic J, Antunovic M, Malekinusic D, Vrdoljak B, Samara M, et al. Stable gastric pentadecapeptide BPC 157 in the treatment of colitis and ischemia and reperfusion in rats: new insights. World J Gastroenterol. 2017; 23(48):8465-88.

83. Belosic Halle Z, Vlainic J, Drmic D, Strinic D, Luetic K, Sucic M, et al. Class side effects: decreased pressure in the lower oesophageal and the pyloric sphincters after the administration of dopamine antagonists, neuroleptics, anti-emetics, L-NAME, pentadecapeptide BPC 157 and L-arginine. Inflammopharmacology. 2017;25(5):511-22.

84. Luetic K, Sucic M, Vlainic J, Halle ZB, Strinic D, Vidovic T, et al. Cyclophosphamide induced stomach and duodenal lesions as a NO-system disturbance in rats: L-NAME, L-arginine, stable gastric pentadecapeptide BPC 157. Inflammopharmacology. 2017:25(2):255-64.

\section{Publisher's Note}

Springer Nature remains neutral with regard to jurisdictional claims in published maps and institutional affiliations.
Ready to submit your research? Choose BMC and benefit from:

- fast, convenient online submission

- thorough peer review by experienced researchers in your field

- rapid publication on acceptance

- support for research data, including large and complex data types

- gold Open Access which fosters wider collaboration and increased citations

- maximum visibility for your research: over $100 \mathrm{M}$ website views per year

At $\mathrm{BMC}$, research is always in progress.

Learn more biomedcentral.com/submissions 